\title{
Research on the Reasonable Coal Pillar Width and Surrounding Rock Supporting Optimization of Gob-Side Entry under Inclined Seam Condition
}

\author{
Li-li Jiang, ${ }^{1}$ Zeng-qiang Yang ${ }^{D},{ }^{2}$ and Gang-wei $\mathrm{Li}^{3}$ \\ ${ }^{1}$ School of Civil Engineering, Chongqing Vocational Institute of Engineering, Jiangjin, Chongqing 402260, China \\ ${ }^{2}$ School of Transportation Engineering, Jiangsu Vocational Institute of Architectural Technology, Xuzhou, Jiangsu 221116, China \\ ${ }^{3}$ State Key Laboratory of Mining Response and Disaster Prevention and Control in Deep Coal Mines, \\ Anhui University of Science and Technology, Huainan, Anhui 232001, China
}

Correspondence should be addressed to Zeng-qiang Yang; zengqiang5@126.com

Received 8 April 2021; Accepted 7 May 2021; Published 19 May 2021

Academic Editor: Zizheng Zhang

Copyright (c) $2021 \mathrm{Li}$-li Jiang et al. This is an open access article distributed under the Creative Commons Attribution License, which permits unrestricted use, distribution, and reproduction in any medium, provided the original work is properly cited.

In order to study the optimal coal pillar width and surrounding rock control mechanism of gob-side entry under inclined seam condition, the 130205 return air entry adjacent to 130203 gob in Yangchangwan No. 1 well is taken as a typical engineering background. By means of engineering background analysis, theoretical analysis based on inside and outside stress field, numerical simulation by FLAC $^{3 \mathrm{D}}$ software, and in situ industrial test and relevant monitoring methods, the optimal coal pillar width and surrounding rock control technology are obtained. The results show that the influence range of inside stress field is about $12.2 \sim 12.8 \mathrm{~m}$ based on theoretical calculation result; under the influence of $10 \mathrm{~m}$ coal column, the overall deformation of the roadway is relatively small and within the reasonable range of engineering construction, so the width of the coal pillar along the return air roadway is set to $10 \mathrm{~m}$ which is more reasonable; the cross-section characteristics of special-shaped roadway lead to asymmetric stress distribution and fragmentation of surrounding rock, and then the asymmetric surrounding rock control technology under the coupling effect of roof prestressed anchor + high-strength single anchor cable + truss anchor cable support is proposed. The monitoring results of this support method are effective for the maintenance of gob-side entry, and the study conclusions provide new guidance for the surrounding rock control mechanism of gob-side entry under inclined seam conditions.

\section{Introduction}

During the underground coal seam mining process, coal pillar mining is usually realized in the form of open-cut tunneling. Scholars determine the reasonable size of coal pillar through theoretical calculation, numerical simulation, and engineering test and arrange the tunnel in the stress reduction zone, when the coal pillar is in the yielding state but still has the bearing capacity, and can keep the tunnel stable if it is reasonably supported [1-3]. If the width of the coal pillar is not reasonable; it may cause dynamic pressure disaster in the process of roadway boring. Therefore, choosing a reasonable width of coal pillar can improve the coal resource recovery rate and reduce the cost of roadway support under the premise of ensuring roadway safety.
Wilson [4] carried out an analysis on the stability factors of soft rock retrieval roadway and discussed comprehensively the mechanism of roadway soft rock damage under the influence of coal column width and workface retrieval. Bai et al. [5] analyzed the stability of narrow coal pillars along the air-excavated roadway by numerical simulation methods to arrive at a reasonable range of coal pillar widths under specific geological conditions. Xie et al. [6] revealed the effect of coal pillar width change on the distribution and change law of surrounding rock stress and pointed out that the reasonable width of the coal pillar in the guard lane should be less than the critical width of the transfer of stress within the solid coal of the lane gang to the coal pillar. He and Zhang [7] proposed a systematic asymmetric support theory by analyzing the deformation characteristics of the 
surrounding rock along the hollow roadway in large sections. Hou and $\mathrm{Li}$ [8] studied the stability principle of the size structure of the surrounding rock along the air-digging lane. Zha et al. $[9,10]$ analyzed the influence of the basic top fracture location on the narrow coal pillar protection lane and studied the selection criteria of reasonable coal pillar width based on this. Li et al. [11], in order to improve the accuracy of the numerical model calculation, set the mining area as a strain hardening model and the coal column as a strain-softening model according to the mechanical properties of the coal rock body.

In previous studies, vertical stress was used as one of the criteria for determining the stability of the surrounding rock, while usually the crustal movement is dominated by horizontal movement, and it is inherently wrong to ignore the influence of horizontal stress and shear stress to evaluate the stability of the surrounding rock. The second invariant of deviatoric stress $\left(J_{2}\right)$ as a unit of characterization of the magnitude of shear stress and distortion appears to be more relevant for determining the degree of shear damage and integrity of the rock mass. It can be expressed by the combination of the maximum principal stress $\left(\sigma_{1}\right)$, the intermediate principal stress $\left(\sigma_{2}\right)$, and the minimum principal stress $\left(\sigma_{3}\right)$, as follows:

$$
J_{2}=\frac{1}{6}\left[\left(\sigma_{1}-\sigma_{2}\right)^{2}+\left(\sigma_{2}-\sigma_{3}\right)^{2}+\left(\sigma_{3}-\sigma_{1}\right)^{2}\right] .
$$

Many scholars have used the second invariant of deviatoric stress to study the mechanical characteristics of surrounding rock, and some research results have been obtained [12, 13]. In this paper, taking 130205 backwind road of Yangchangwan coal mine as the engineering background, on the basis of theoretical analysis, the influence of coal seam inclination on the roadway surrounding rock is fully considered, and FLAC3D numerical simulation is used to derive the distribution of the main deflection stress and deformation mechanism of the roadway surrounding rock, which provides the basis for the reasonable selection of coal pillar width.

\section{Engineering Situations}

130205 working face is located in the eastern part of the well field of Yangchangwan No.1 well, the adjacent 130203 working face in the upper part of the 130205 working face has been mined out, and a $20 \mathrm{~m}$ width of coal pillar was left to protect the 130205 return air entry. The burial depth of 130205 working face is about $587.1 \sim 726.7 \mathrm{~m}$, and the average burial depth is $656.9 \mathrm{~m}$. Its primary mineable coal bed is the No.2 coal seam, the thickness of this coal seam is about $8.2 \sim 10.7 \mathrm{~m}$, and the average thickness of this coal seam is $8.4 \mathrm{~m}$. The layout plan of 130203 fully mechanized working face is shown in Figure 1.

\section{Theoretical Analysis of Narrow Coal Pillar Width}

3.1. Relationship between the Position of the Basic Top Breaking Line and the Width of the Coal Column. With the advance of the upper section of the working face, the basic top of the edge of

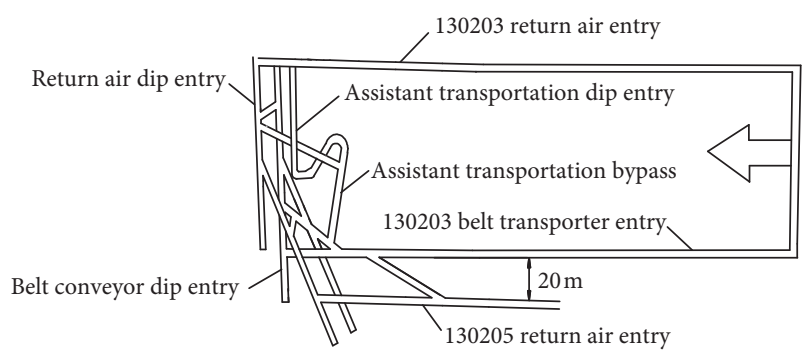

FIgURE 1: 130203 fully mechanized working face layout plan.

the mining area breaks until it touches the gangue, gangue to the basic top to form a preliminary support role, and the adjacent blocks bite each other to form an articulated structure, which is relatively stable by the horizontal thrust of the adjacent rock blocks [14-16]. According to the "internal-external stress field" mine pressure theory that was put forward by Song et al. [17], the break line again divides the lateral coal body into 2 parts, one of which is the internal stress field determined by the weight of the moving rock beam, and the other is the external stress field associated with the overall force of the overlying rock, where a new plastic and elastic zone is again formed within the external stress field, as shown in Figure 2. The mechanical model can be obtained by simplifying Figure 2, as shown in Figure 3 .

From Figure 3, the support pressure in the internal stress field at a distance $x$ from the edge of the coal wall is shown as follows:

$$
\sigma_{y}=G_{x} \cdot y_{x}
$$

where $G_{x}$ is the stiffness of the coal seam at a distance $x$ from the coal wall in the internal stress field $(\mathrm{Pa})$ and $y_{x}$ is the compression of the coal body at a distance $x$ from the coal wall in the internal stress field $(m)$.

Reducing this to a linearly varying process, the geometric relationship yields as follows:

$$
\begin{aligned}
y_{x} & =\frac{y_{0}}{x_{0} / \cos (\theta-\psi)} \cdot\left(\frac{x_{0}}{\cos (\theta-\psi)}-\frac{x}{\cos (\theta-\psi)}\right), \\
G_{x} & =\frac{G_{0}}{x_{0}} x,
\end{aligned}
$$

where $y_{0}$ is the maximum compression at the coal wall at the edge of the mining area $(m) ; \theta$ is the dip angle of the coal seam, set at $13^{\circ}$ according to the mine data; $\psi$ is the break angle between the rock seams when the key block B breaks, which is $5^{\circ} \sim 7^{\circ}$ according to the actual measurement; $x_{0}$ is the size of the internal stress field range of this coal seam $(m)$.

Combining equations (2) and (3), the support stress component of the internal stress field in the direction perpendicular to the coal bed roof can be obtained as follows:

$$
\int_{0}^{x_{0} \cdot \cos (\theta-\psi)} \sigma_{y}=G_{0} y_{0} x_{0}\left(\frac{\cos ^{2}(\theta-\psi)}{2}-\frac{\cos ^{3}(\theta-\psi)}{3}\right) .
$$

The direction of the supporting stress of the internal stress field is vertical downward, so the magnitude of the 


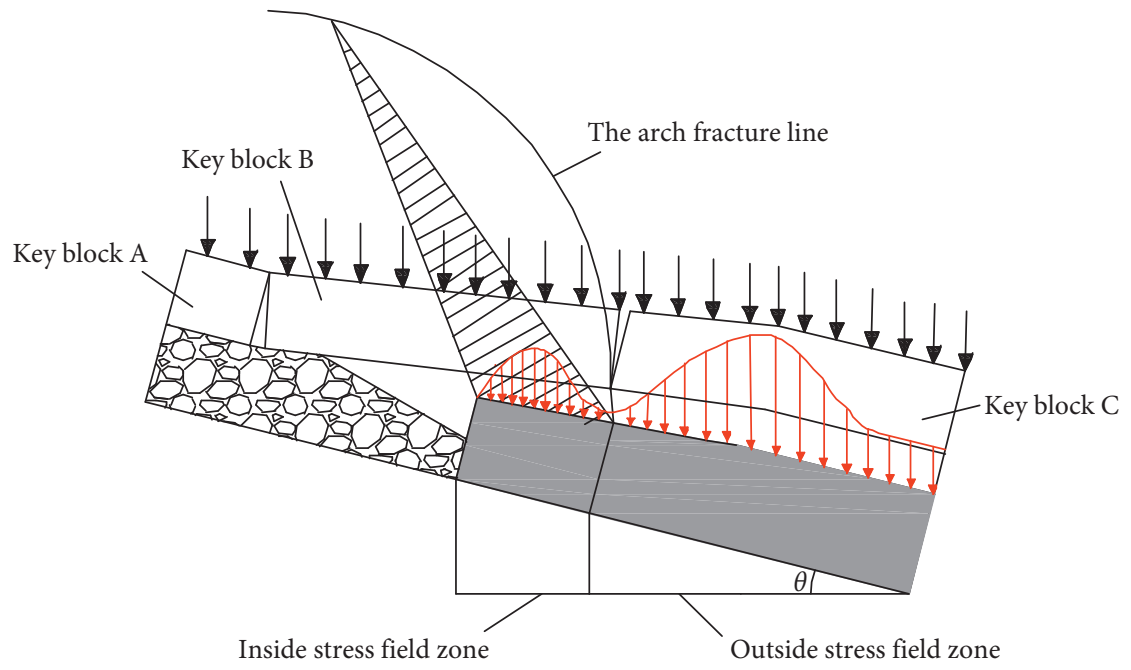

FIgURE 2: Lateral abutment stress distribution along dip direction in coal mass adjacent to gob.

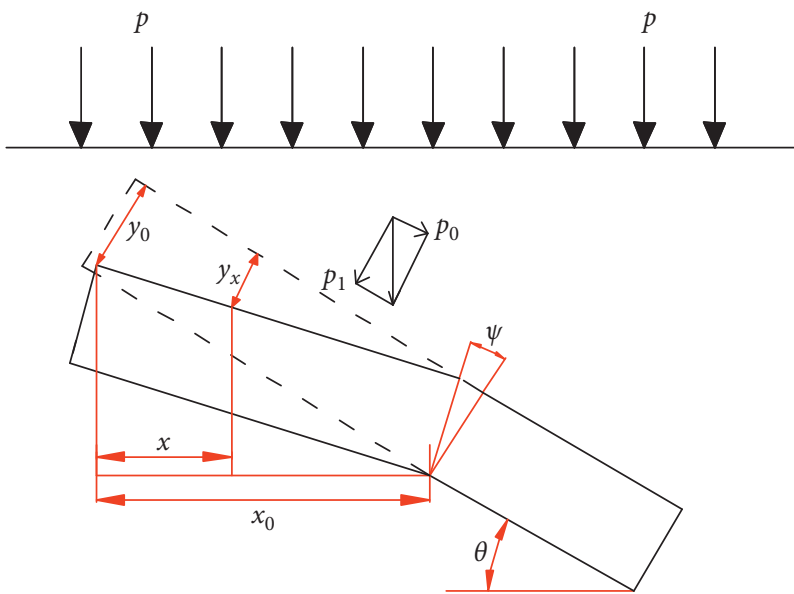

Figure 3: The basic roof fracture structure and stress condition above coal mass adjacent to gob.

supporting stress within the range of the internal stress field is shown as follows:

$$
\frac{G_{0} y_{0} x_{0} \cdot\left(\left(\cos ^{2}(\theta-\psi) / 2\right)-\left(\cos ^{3}(\theta-\psi) / 3\right)\right)}{\cos \psi} .
$$

The support stress within the internal stress field is approximated as the weight of the basic top rock layer in the range of the internal stress field when incoming pressure occurs, i.e.,

$$
\frac{G_{0} y_{0} x_{0} \cdot\left(\left(\cos ^{2}(\theta-\psi) / 2\right)-\left(\cos ^{3}(\theta-\psi) / 3\right)\right)}{\cos \psi}=L C_{0} M \gamma,
$$

where $L$ is the length of the working face of the upper section $(m) ; C_{0}$ is the incoming pressure step of the working face $(m) ; M$ is the thickness of each transfer rock beam $(m) ; \gamma$ is the average capacity of each transfer rock beam $\left(\mathrm{kN} / \mathrm{m}^{3}\right)$. From the beginning of the collapse of the direct top until the end of the gangue process, as the deformation of the coal seam and the direct top is synchronized, the geometric relationship can be obtained as follows:

$$
\frac{y_{0}}{x_{o} / \cos (\theta-\psi)}=\frac{\Delta h}{L^{\prime} / \cos (\theta-\psi)}=\frac{h-m_{z}\left(K_{p}-1\right)}{L^{\prime} / \cos (\theta-\psi)}
$$

where $\Delta L$ is the maximum sinkage when the direct top touches the gangue stability $(m) ; L^{\prime}$ is the span of the direct top hinge rock beam $(m) ; h$ is the mining height of the seam $(m) ; m_{z}$ is the collapse height of the broken direct top $(m) ; K_{p}$ is the broken expansion coefficient of the basic top rock.

The stiffness $G_{0}$ of the coal body in the plastic state can be expressed by the envelope theory as follows:

$$
G_{0}=\frac{E}{2(1+v) \zeta}
$$

where $E$ is the modulus of elasticity of coal body $(P a) ; v$ is Poisson's ratio; $\xi$ is the influence coefficient, which is related to the fracture development in the coal body. 
The magnitude of the internal stress field can be obtained by combining the above equations as follows:

$$
x_{0}=\sqrt{\frac{12 L C_{0} M \gamma(1+v) \zeta L^{\prime} \cos \psi}{E\left[h-m_{Z}\left(K_{p}-1\right)\right] \cdot\left[3 \cos ^{2}(\theta-\psi)-2 \cos ^{3}(\theta-\psi)\right]}} .
$$

According to the geological data of the mine and field measurements, it is known that $L=170 \mathrm{~m}, C_{0}$ is $32 \sim 35 \mathrm{~m}$, $M=12.8 \mathrm{~m}$, and $\gamma=27 \mathrm{kN} / \mathrm{m}^{3}, v=0.27, \xi=0.8, L^{\prime}=18 \sim 21 \mathrm{~m}$, $E=2.5 \mathrm{GPa}, h=4.5 \mathrm{~m}, m_{z}=4.1 \mathrm{~m}, K_{p}=1.7$, and $\theta=13^{\circ}$. The internal stress field can be found in the range of 12.2 to $12.8 \mathrm{~m}$. The internal stress field is in a low stress range; if the roadway is arranged within the internal stress field range by using the roadway along the air boring, it can effectively improve the mechanical state of the roadway surrounding rock, improve the stability of the roadway, and reduce the roadway maintenance cost.

3.2. Preliminary Determination of Coal Pillar Width of Inclined Coal Seam. Usually, the basic top fracture line is located in the coal wall at $0 \sim 14 \mathrm{~m}$. When the fracture line is located in the coal wall at 9 14 m, generally $1 \sim 5 \mathrm{~m}$ coal pillar is used to arrange the roadway along the empty roadway within the fracture line; at this time, the sum of the width of the roadway along the empty roadway and the width of the narrow coal pillar is less than the width of the "internal stress field", so that the roadway is in the low stress area. However, in addition to the support pressure factor, the influence of the size of the stable area inside the narrow coal column and the influence of the sheet gang, water accumulation in the mining area, and uneven strength of the coal body on the stability of the narrow coal column should also be considered.

(1) Yangchangwan coal mine No.2 coal seam belongs to the inclined coal seam, above the mining area gangue along the coal seam tendency to have downward pressure on the coal pillar, and there is a certain range of plastic damage area at the coal wall, the coal pillar internal fissure is developed, and stability is poor, so leaving 1 5 $\mathrm{m}$ coal pillar cannot ensure that the coal pillar can exist in the elastic core area of the main bearing capacity

(2) Because the combustion point of No.2 coal is relatively low, it is especially important to reduce the degree of fissure development in the coal column in order to prevent the spontaneous combustion of residual coal caused by the leakage of wind from the return air tunnel to the mining area

Considering the role of the coal pillar to block gangue, waterproof, fire prevention, gas, etc., the protective coal pillar is at least set at $3 \sim 5 \mathrm{~m}$. In order to meet the normal working design of the shaft width of $5 \mathrm{~m}$, the width of the coal pillar is initially set at $8 \sim 10 \mathrm{~m}$. The $8 \sim 10 \mathrm{~m}$ protective coal pillar is left and the roadway is arranged within $2 \sim 3 \mathrm{~m}$ below the basic top fracture line, which effectively avoids the huge load transmitted down by the arch foot and keeps the surrounding rock of the roadway relatively stable after digging.

\section{Numerical Simulation}

4.1. Establishment of the Numerical Simulation Model. According to the production geological condition of 130205 working face, a FLAC ${ }^{3 \mathrm{D}}$ numerical model is established, as shown in Figure 4. The model is fixed at the two boundaries of the $X$ and $Y$ axes and the bottom boundary of $Z$ axis, a selfweight load of $17.625 \mathrm{MPa}$ is applied directly above the model $Z$ axis, and the lateral pressure coefficient is set to 1.2, which is confirmed by in situ stress test results. The rock parameters were obtained by evolutionary analysis based on the measured results. The coal seam model was set as the Mohr-Coulomb strain-softening model [18, 19], and the rock mechanical parameters of the coal seam and surrounding rocks are listed in Table 1.

\subsection{The Second Invariant of Deviatoric Stress Field Distribution}

4.2.1. Distribution of Second Invariant of Deviatoric Stress in Coal Pillar Affected Area of the Roadway Surrounding Rock. The second invariant of deviatoric stress represents the magnitude of the shear force and deformation of the rock body, which can objectively reflect the essential characteristics of the deformation and damage of the surrounding rock caused by the excavation of the roadway $[13,20]$. It is more comprehensive than the previous use of only the support pressure (vertical stress) as a measure. The weight of the overlying rock in the mining void area of the middle and upper section of the inclined coal seam is transferred to the side of the coal pillar by means of a fracture arch, so the width of the coal pillar is crucial to the mechanical state of the surrounding rock along the empty roadway. The simulation studies the second invariant of deviatoric stress cloud at $Y=80 \mathrm{~m}$ cut for coal column widths of 5, 8, 10, 12.5, 15, and $20 \mathrm{~m}$, respectively, as shown in Figure 5.

4.2.2. Coal Seam Tendency Second Invariant of Deviatoric Stress Distribution State. By monitoring the magnitude of $\sigma_{1}, \sigma_{2}$, and $\sigma_{3}$ stresses at the location of the coal pillar and solid coal midline, the second invariant of deviatoric stress under the influence of different coal pillars is calculated and plotted, as shown in Figure 6.

From Figure 6(a), the following can be seen:

(1) The peak value of the second invariant of deviatoric stress shows a trend of increasing first and then decreasing. For the coal pillar in the section of $5 \sim 12.5 \mathrm{~m}$, with the increase of the width of the coal pillar, the peak value of the second invariant of deviatoric stress in the coal pillar shows a "positive correlation" growth. For the coal pillar in the $12.5-20 \mathrm{~m}$ section, the curve shape changes from "single peak" to "double hump" as the width of the coal pillar increases, and the peak of the second 


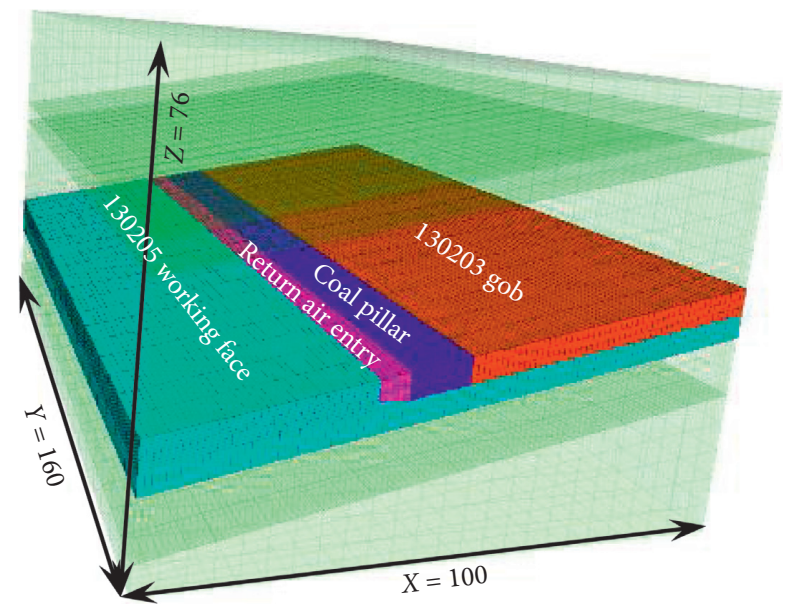

FIgURE 4: The establishment of a three-dimensional numerical model by FLAC3D software.

TABLE 1: Testing result of coal samples about physical and mechanical properties.

\begin{tabular}{|c|c|c|c|c|c|c|}
\hline Types & $\begin{array}{l}\text { Density } \\
\left(\mathrm{g} \cdot \mathrm{cm}^{-3}\right)\end{array}$ & $\begin{array}{l}\text { Bulk modulus } \\
(\mathrm{GPa})\end{array}$ & $\begin{array}{l}\text { Shear modulus } \\
(\mathrm{GPa})\end{array}$ & $\begin{array}{c}\text { Cohesion } \\
(\mathrm{MPa})\end{array}$ & $\begin{array}{c}\text { Internal friction angle } \\
\left({ }^{\circ}\right)\end{array}$ & $\begin{array}{c}\text { Thickness } \\
(\mathrm{m})\end{array}$ \\
\hline Fine sandstone & 2.70 & 13.3 & 10 & 10.2 & 37 & 5.0 \\
\hline $\begin{array}{l}\text { Medium } \\
\text { sandstone }\end{array}$ & 2.34 & 12.3 & 9.1 & 5.2 & 37 & 13.0 \\
\hline Fine sandstone & 2.70 & 13.3 & 10 & 10.2 & 37 & 5.0 \\
\hline Siltstone & 2.65 & 9.1 & 7.8 & 7.2 & 34 & 5.0 \\
\hline Carbon mudstone & 2.54 & 8.4 & 5.7 & 8.0 & 36 & 1.5 \\
\hline 2\# coal & 1.30 & 5.0 & 2.1 & 1.68 & 28 & 8.5 \\
\hline Siltstone & 2.65 & 9.1 & 7.8 & 7.2 & 34 & 5.0 \\
\hline Mudstone & 2.25 & 6.8 & 4.8 & 6.2 & 26 & 2.0 \\
\hline Fine sandstone & 2.70 & 13.3 & 10 & 10.2 & 37 & 5.0 \\
\hline
\end{tabular}

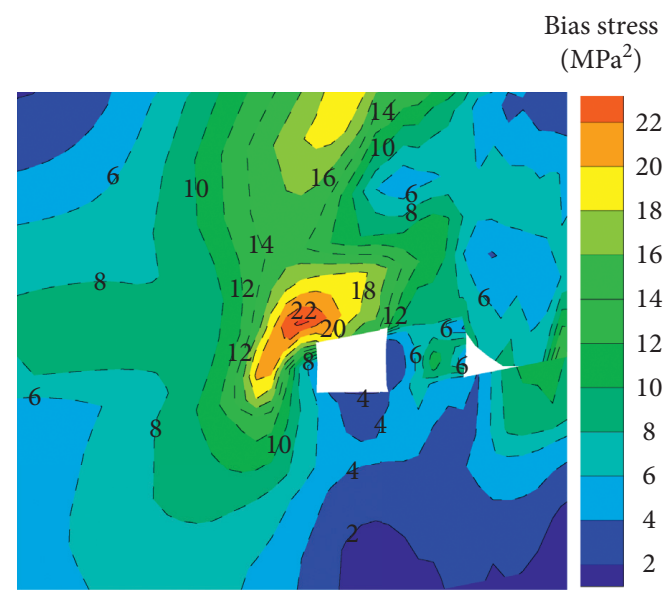

(a)

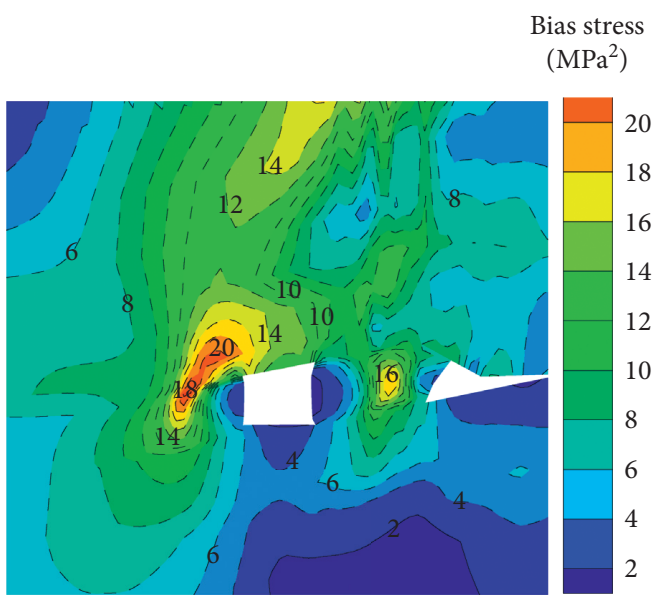

(b)

FIgURE 5: Continued. 
Bias stress $\left(\mathrm{MPa}^{2}\right)$

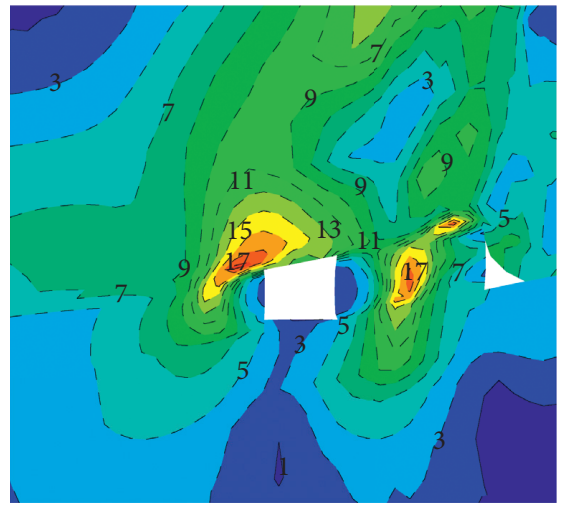

(c)

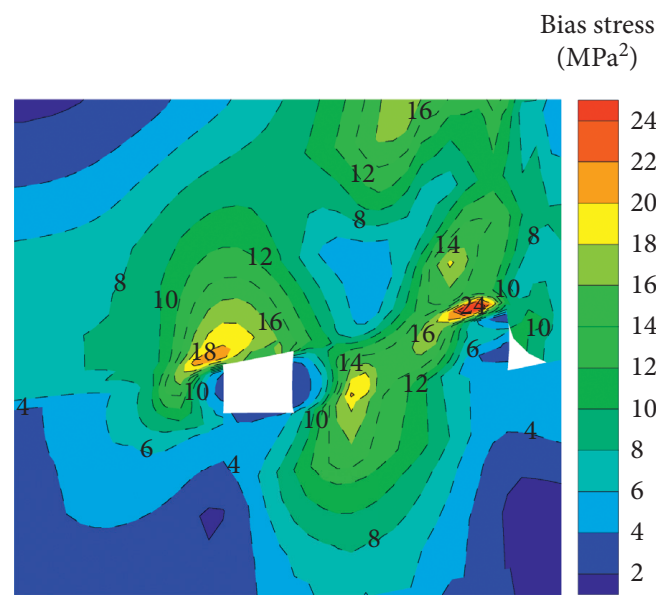

(e)

as stress
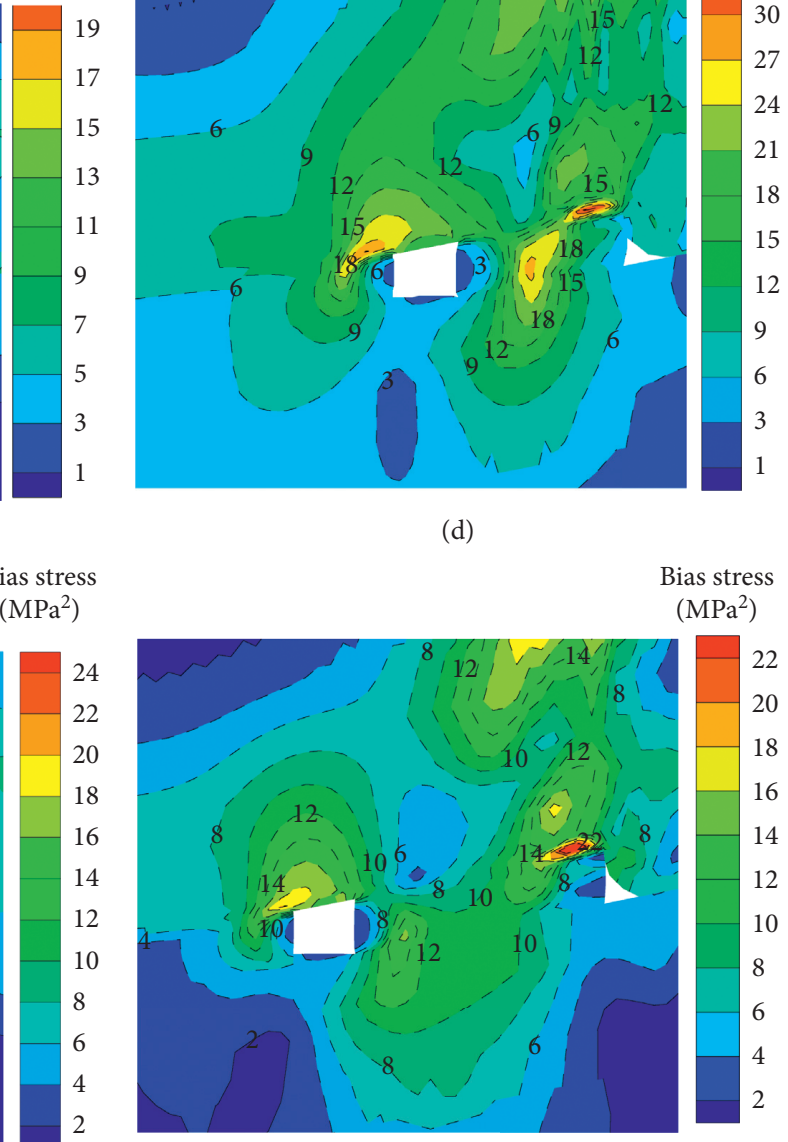

(f)
$\left(\mathrm{MPa}^{2}\right)$

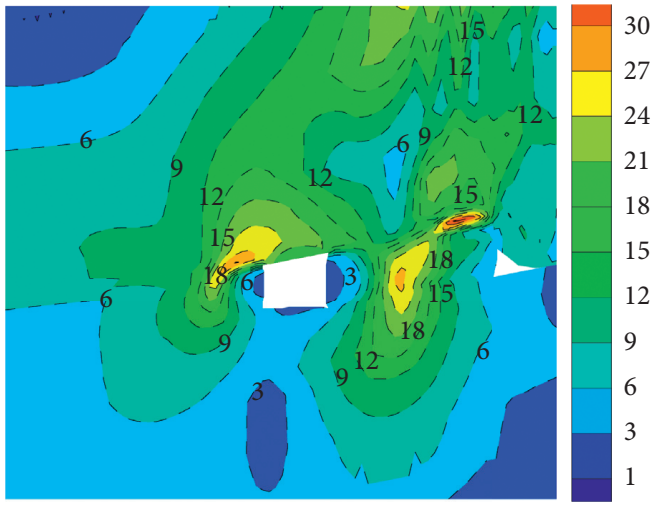

(d)

Bias stress $\left(\mathrm{MPa}^{2}\right)$

Figure 5: The second invariant of deviatoric stress cloud in the surrounding rock of the roadway under different width coal pillars. (a) $5 \mathrm{~m}$ coal pillar, (b) $8 \mathrm{~m}$ coal pillar, (c) $10 \mathrm{~m}$ coal pillar, (d) $12.5 \mathrm{~m}$ coal pillar, (e) $15 \mathrm{~m}$ coal pillar, and (f) $20 \mathrm{~m}$ coal pillar.

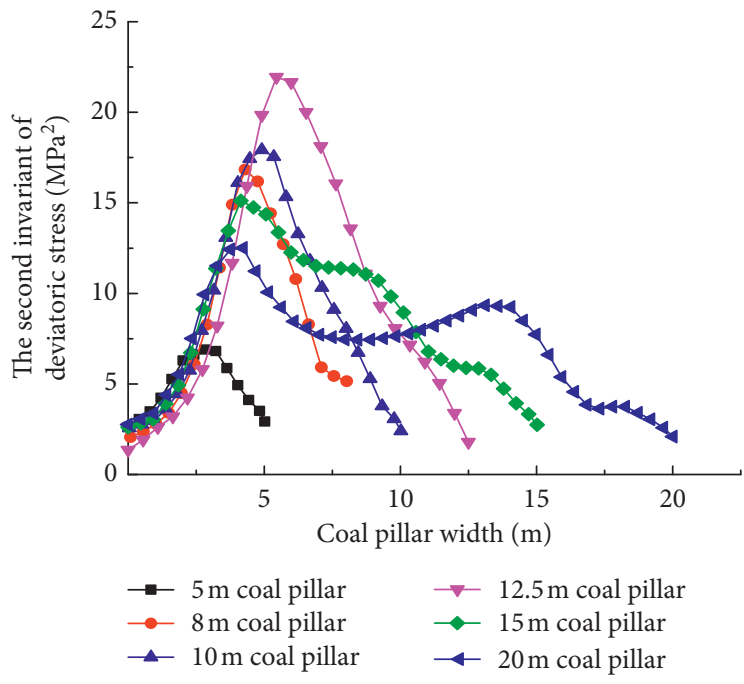

(a)
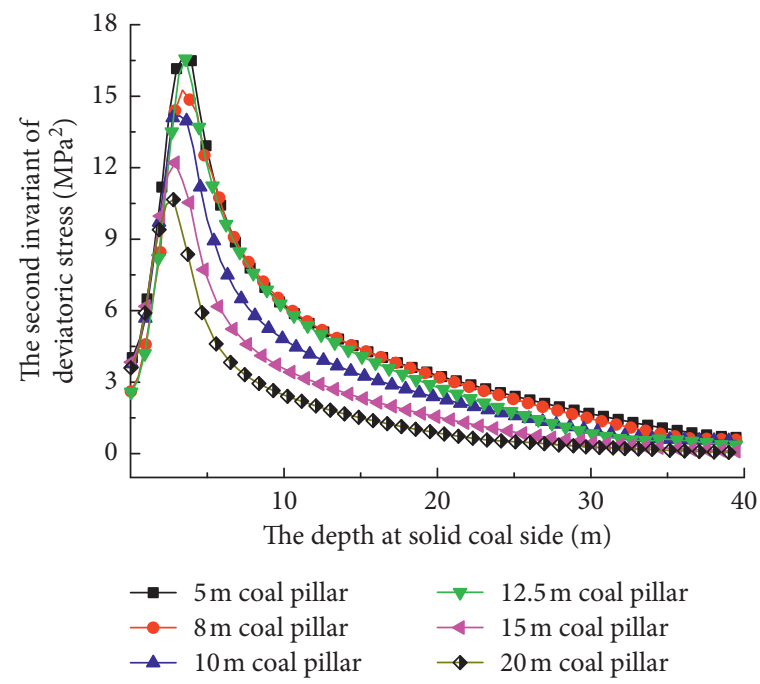

(b)

Figure 6: The second invariant of deviatoric stress distribution curves in the two coal girders of the roadway under different width coal pillars. (a) Coal pillar side. (b) Solid coal side. 
invariant of deviatoric stress in the coal pillar shows a "negative correlation" with the width of the coal pillar

(2) The peak location of the second invariant of deviatoric stress also shows a trend of increasing and then decreasing

For the coal pillars in the $5 \sim 12.5 \mathrm{~m}$ section, as the width of the pillar increases, the location of the peak appears at a linear increase from the horizontal distance of the roadway, with the peak location shifting away from the roadway. For the coal column in the 12.5 20 section, the hump shape starts to appear when the coal column equals $15 \mathrm{~m}$. At this time, the peak of the hump is almost equal, which is called the "positive trapezoid" shape here. Thus, within this range of coal pillars, the shape of the second invariant of deviatoric stress distribution undergoes a transformation from single hump - orthotropic shape-double hump, and the interior of large coal pillars is more complete, which also indirectly reveals the reason for the feasibility of traditional large coal pillars.

From Figure 6(b), the following can be seen:

(1) The overall second invariant of deviatoric stress in the solid coal shows the "asymmetric" characteristic of increasing first and then decreasing, and the coal pillars of different widths have a tendency to converge within $40 \mathrm{~m}$ of the surrounding rock on the side of the solid coal. The magnitude of the second invariant of deviatoric stress in the coal body $40 \mathrm{~m}$ away is almost 0 , and the coal body in this range is approximately in the original rock stress zone

(2) Overall, with the increase of the width of the left coal pillar, the peak of the second invariant of deviatoric stress within the solid coal decreases and the stress has a tendency to transfer from the solid coal side to the coal pillar side. As the width of the coal column increases, the corresponding peak position of the solid coal side as a whole shows a negative linear correlation law with it

4.2.3. Characteristics of Top Plate's Second Invariant of Deviatoric Stress Distribution. In order to analyze the distribution characteristics of the second invariant of deviatoric stress in the surrounding rock of the tunnel roof, a total of 3 monitoring lines were set up, each line set up a monitoring point at $0.5 \mathrm{~m}$ interval, each line has a total of 40 monitoring points, and the roof monitoring line was laid out as Figure 7, using the formula which is shown in equation (1) to find out the second invariant of deviatoric stress and postprocessed to obtain curve in Figure 8.

The following pattern can be derived from Figure 8:

(1) When the coal column is stable and the width of the coal column is small, the shallow surrounding rock above the roof of the roadway has a higher second invariant of deviatoric stress, and with the increase of the surrounding rock depth, the stress increases

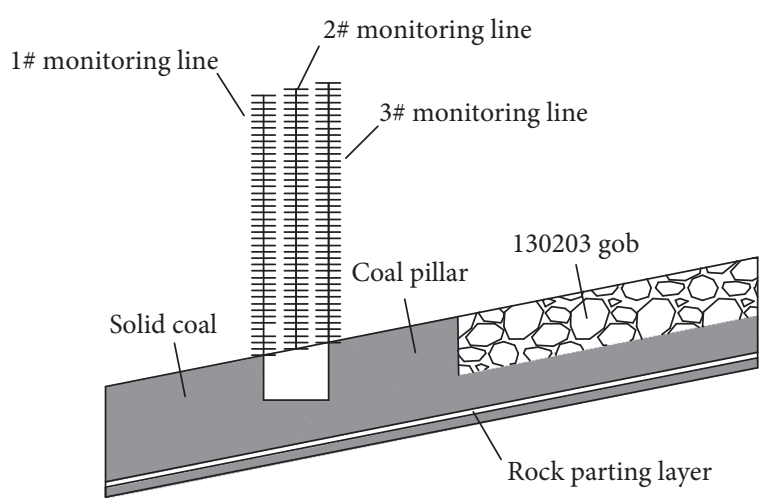

FIGURE 7: Monitoring point arrangement plan in the roof of the roadway.

again after the second invariant of deviatoric stress decreases to a certain minimal value, and a higher stress concentration zone appears, and the wider the coal column is, the smaller the peak of this influence zone is

(2) When the coal column is stable and the width of the coal column is large, the shallow surrounding rock above the roof of the roadway has a low value of the second invariant of deviatoric stress compared with the narrow coal column, the shallow surrounding rock is more stable and does not form a strong shear stress concentration area, and the integrity of the roof of the roadway is better under this large coal column. As the depth of the surrounding rock increases, due to the distance from the mining area, the influence of stress in the adjacent mining area is relatively small, and there is an overall "negative exponential" relationship between the value of the second invariant of deviatoric stress and the increase in the depth of the surrounding rock

(3) The different horizontal distance between the three monitoring lines and the mining area directly affects the size and location of the peak of the second invariant of deviatoric stress. It can be seen that (1) the degree of damage to the surrounding rock on the top plate monitoring line 3 is much greater than that on the monitoring line 1 , and the shear fragmentation of the shallow part of the top plate shows significant asymmetric characteristics; (2) the surrounding rocks of the three monitoring lines under different width coal pillars differ greatly in the peak value of the second invariant of deviatoric stress due to the influence of adjacent mining areas. When the coal pillar width is $5 \sim 8 \mathrm{~m}$, the minimum peak second invariant of deviatoric stress under the influence of $8 \mathrm{~m}$ coal pillar is 12.42 $\mathrm{MPa}$ when monitoring the surrounding rock of line 1 under the influence of adjacent mining area, which is $9.74 \%$ lower than the peak at $5 \mathrm{~m}$ coal pillar. When the width of the coal pillar is $5 \sim 10 \mathrm{~m}$, the minimum peak of the second invariant 


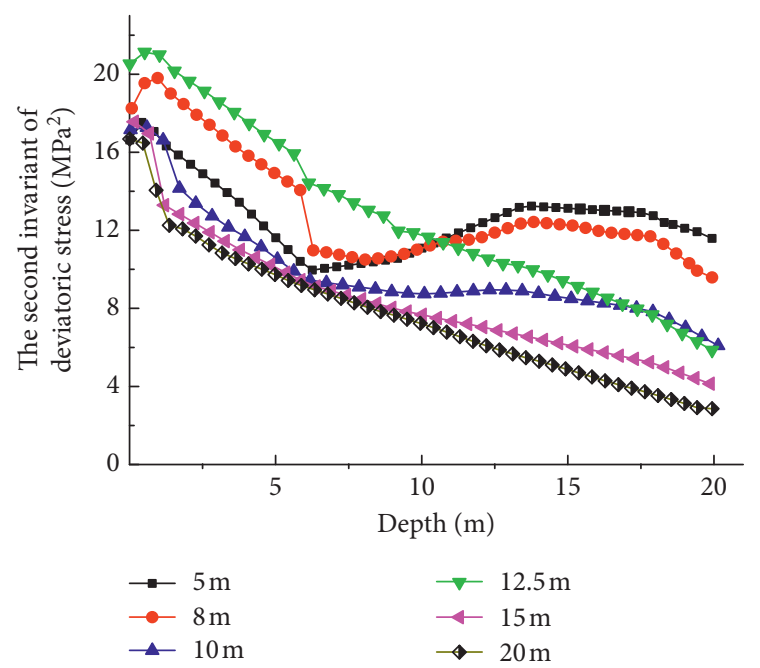

(a)

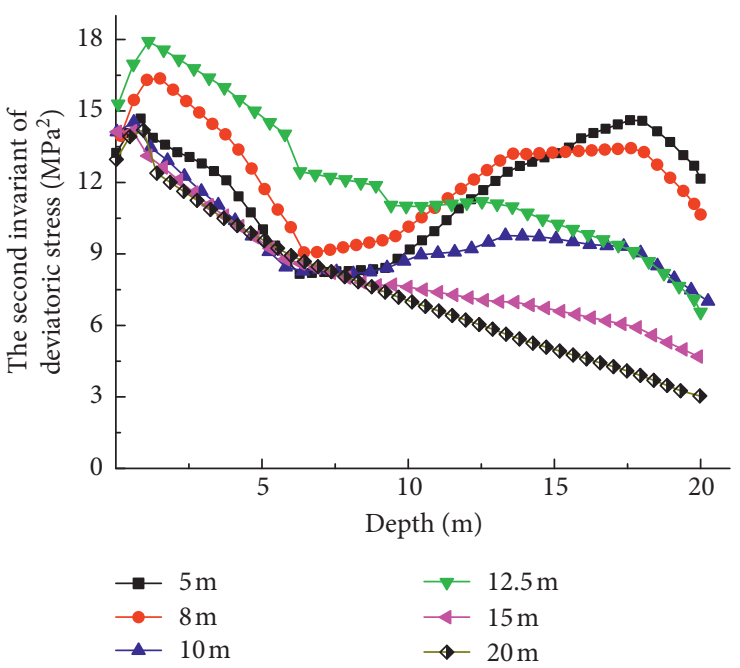

(b)

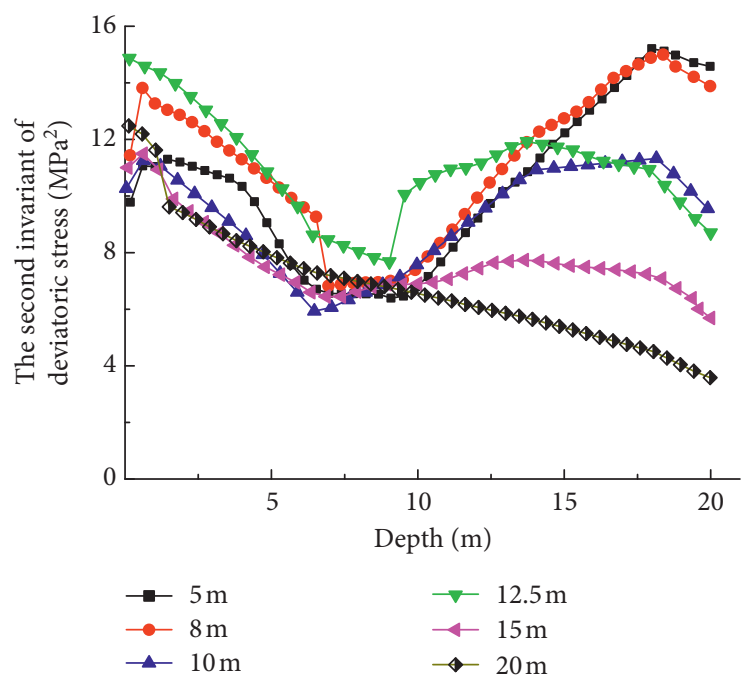

(c)

Figure 8: The second invariant of deviatoric stress curve by top slab surrounding rock monitoring line. (a) $1^{\#}$ monitoring line. (b) $2^{\#}$ monitoring line. (c) $3^{\#}$ monitoring line.

of deviatoric stress under the influence of $10 \mathrm{~m}$ coal pillar is $9.31 \mathrm{MPa}$ in the surrounding rock of monitoring line 2 by the adjacent mining area, which is $36.28 \%$ lower than the peak of $5 \mathrm{~m}$ coal pillar; the minimum peak of the second invariant of deviatoric stress under the influence of $10 \mathrm{~m}$ coal pillar is $11.32 \mathrm{MPa}$ in the surrounding rock of monitoring line 3 , which is $25.58 \%$ lower than the peak of $5 \mathrm{~m}$ coal pillar; (3) under the influence of $10 \mathrm{~m}$ coal pillar, the surrounding rock of monitoring line is less influenced by the upper section of mining area, and shear damage is not big; from the safety point of view, choosing this width coal pillar is more conducive to the stability of the roof

\subsection{Deformation Characteristics of the Tunnel Surrounding Rock}

4.3.1. Displacement Distribution State within the Coal Column. In order to investigate the reasonableness of the width of the coal pillar left between 130205 along the empty road and the upper section of the mining area, the characteristics of the horizontal displacement distribution within the coal pillar of different widths were selected as the object of study, as shown in Figure 9. The following can be seen:

(1) In the side close to the mining area, the displacement of the coal body to the mining area is more obvious, and it can be seen from Figure 9(b) that when the width of the coal column is less than $5 \mathrm{~m}$, there is a 


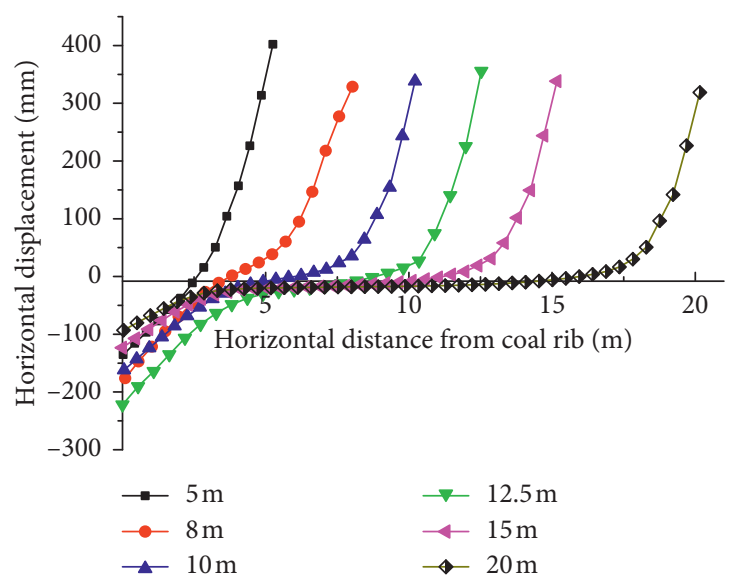

(a)

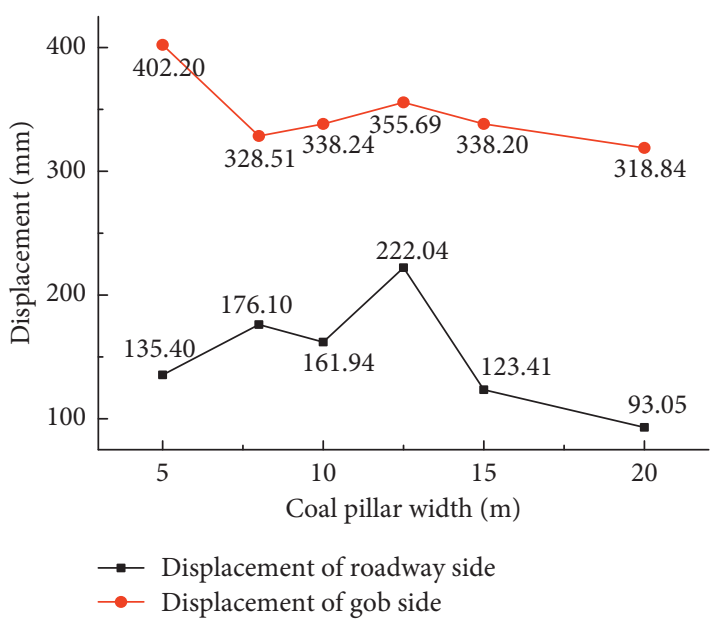

(b)

FIGURE 9: Horizontal displacement distribution curves under coal column of different widths. (a) Coal pillar midline displacement curve. (b) Maximum displacement value on both sides of the coal column.

large displacement of the coal column along the direction of the coal seam inclination on the side of the mining area, and at this time, the coal column is broken seriously and thrown down to the mining area. Under the influence of $8 \mathrm{~m}$ and $10 \mathrm{~m}$ coal pillar, the displacement of coal pillar to the mining area is greatly relieved compared with $5 \mathrm{~m}$ coal pillar, and then with the increase of coal pillar width, although it can reduce the degree of breakage within the coal pillar, its overall effect is not obvious

(2) From Figure 9(b), it can be seen that under the influence of $12.5 \mathrm{~m}$ coal pillar, the maximum displacement of $222.04 \mathrm{~mm}$ is generated on the side of the mining area, the minimum displacement is $93 \mathrm{~mm}$ at $20 \mathrm{~m}$ coal pillar, and the overall displacement curve approximately forms a "single hump" shape

(3) As seen in Figure 9(a), when the coal column width is $10 \mathrm{~m}$, continuous $0 \mathrm{~mm}$ displacement points start to appear within the coal column. The elastic nucleus zone without displacement is extremely important to the stability of the coal column. The elastic nucleus zone has strong stability under the mutual extrusion of the surrounding coal body, which can effectively avoid gas protrusion and wind leakage and other disasters and facilitate the management and maintenance of the roadway

Therefore, the necessity of narrow coal pillars for the stability of the roadway can be seen. The elastic core zone with very small displacement starts to appear within the $10 \mathrm{~m}$ coal pillars, the elastic core zone plays the main bearing role for the overlying rock layer, and its width is inseparable from the stability of the dug tunnel and the high maintenance cost at a later stage. Therefore, the width of the coal pillar is initially set at $10 \mathrm{~m}$ from the consideration of the internal stability of the coal pillar alone.

4.3.2. Deformation Law of the Surrounding Rock along the Air Dug Tunnel. The monitoring points are set up at the two helpers of the roadway, the two ends of the top and bottom plates, and the midline, respectively, and the displacement curve shown in Figure 10 is obtained, which shows the following:

(1) The sinkage of the roof slab: as the width of the coal pillar increases, the sinking amount of roof monitoring point on the side of the coal pillar is always larger than that on the side of solid coal. Therefore, it is necessary to reasonably arrange anchor support near the roof of the coal pillar, so that it can form a "small structure" with a shallow surrounding rock to fully improve the residual strength of the surrounding rock and improve the stress environment of the surrounding rock

(2) Bottom drum volume: 130205 backwind lane bottom slab is loose and soft; in the process of stress distribution of surrounding rock caused by lane excavation to the new balance of stress, the bottom slab coal keeps bulging into the lane space, compared to the direct bottom as the lane bottom slab will form a larger bottom drum volume

(3) The displacement of the coal pillar gang: from the overall view of the curve, the displacement of the coal pillar gang is most obvious at the midline, the displacement of the shoulder angle of the coal pillar gang is small and does not change significantly, and the overall displacement of the bottom angle of the coal pillar gang shows a trend of increasing first and then decreasing 


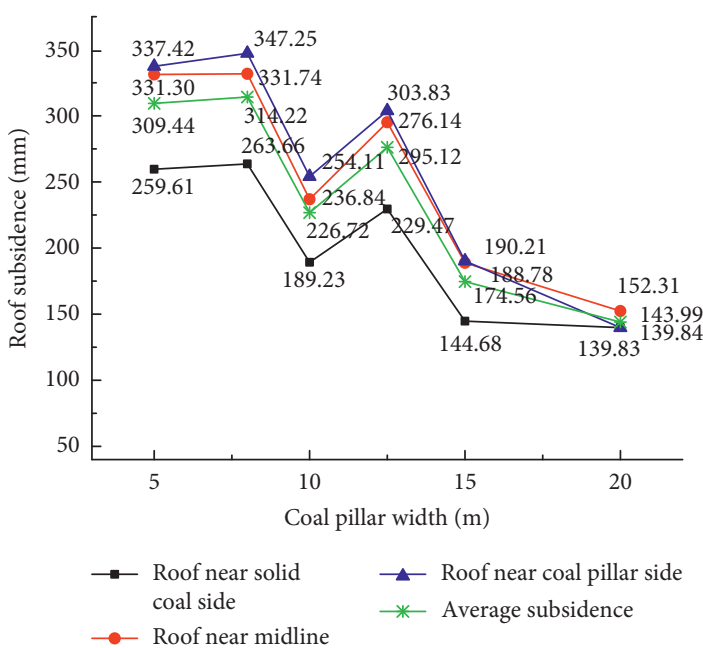

(a)

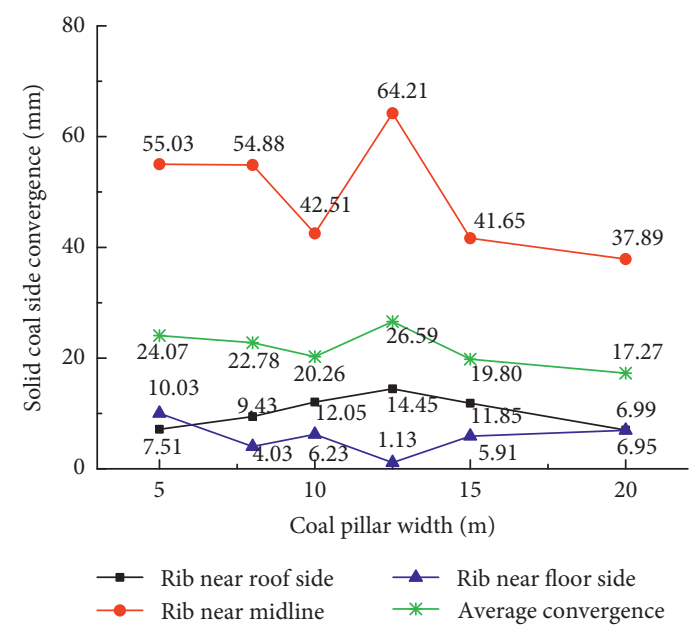

(c)

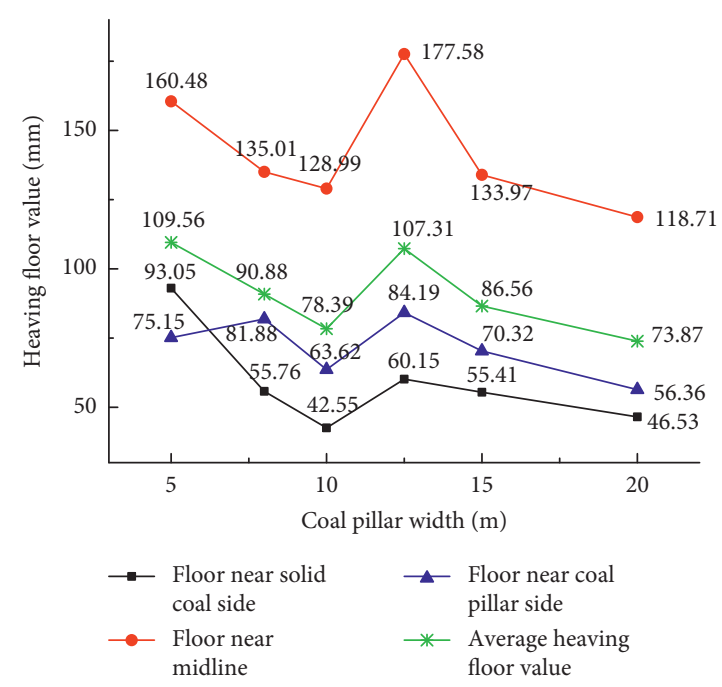

(b)

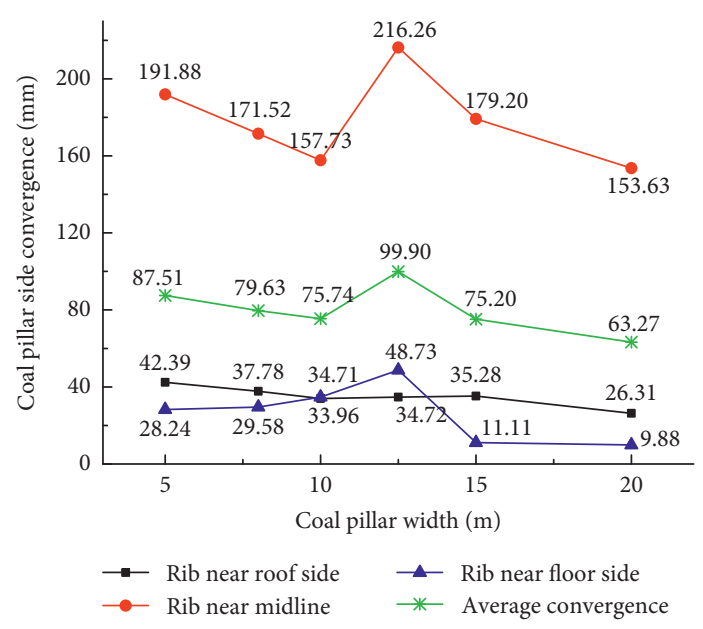

(d)

Figure 10: Variation of the displacement of the surrounding rock of the roadway under different width coal pillars. (a) Top plate sinkage. (b) Bottom drum volume. (c) Coal pillar gang approach amount. (d) Solid coal gang approach amount.

(4) The amount of solid coal gang migration: from the average displacement data, the influence of coal pillar width on the solid coal gang is not significant, under the influence of $12.5 \mathrm{~m}$ coal pillar, the displacement of the solid coal gang reaches the maximum $17.73 \mathrm{~mm}$, under the influence of $15 \sim 20 \mathrm{~m}$ large coal pillar, the displacement decreases, and under the influence of $20 \mathrm{~m}$ coal pillar, the average displacement of the solid coal gang reaches the minimum $9.29 \mathrm{~mm}$

In summary, the variation of coal pillar width along the air dug tunnel has a greater impact on the amount of roof sinking, bottom bulge, and coal pillar gang displacement in the 130205 return tunnel. Under the influence of $10 \mathrm{~m}$ coal column, the overall deformation of the roadway is relatively small and within the reasonable range of engineering construction, which can fully meet the basic roadway transportation, ventilation, and pedestrian requirements, the internal coal column is more stable and the stress carried above the coal column is relatively small, and the roadway roof is less affected by the superimposed stress of the adjacent mining area, so the width of the coal column along the air dug roadway is set to $10 \mathrm{~m}$ which is more reasonable.

\section{Roadway Rock Control Technology and Practice}

5.1. Rock Control Technology along the Empty Roadway. Based on the numerical simulation results and combined with the actual mine production requirements, the causes of maintenance difficulties in the 130205 return airway can be summarized as follows:

(1) The coal pillar plays an extremely important role in supporting the overlying rock as the support point of the fracture arch from the time the roadway is dug until the coal pillar is stabilized. Because the coal body has strain-softening characteristics, so in the 


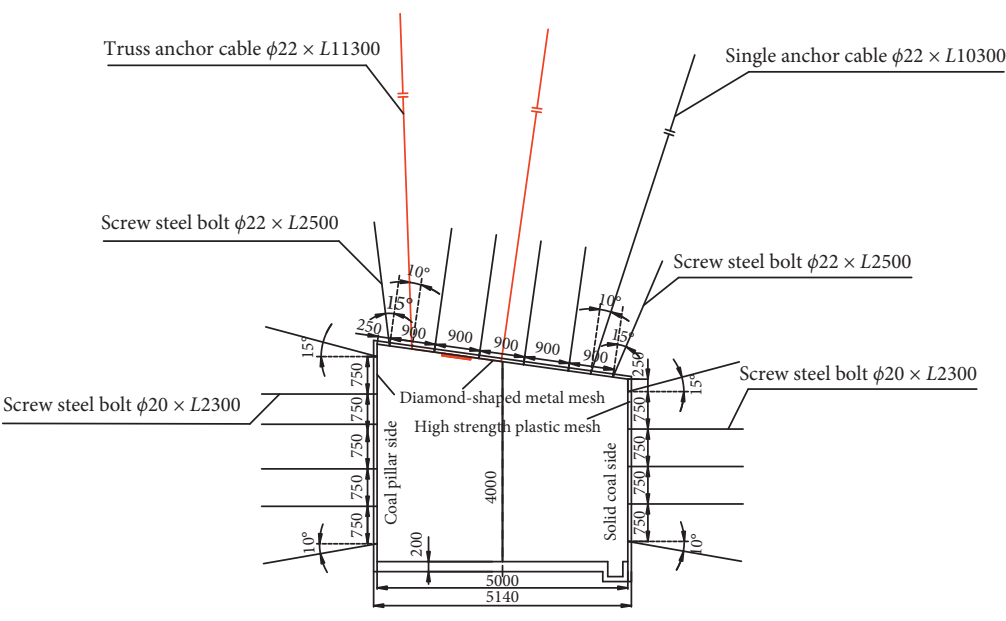

(a)

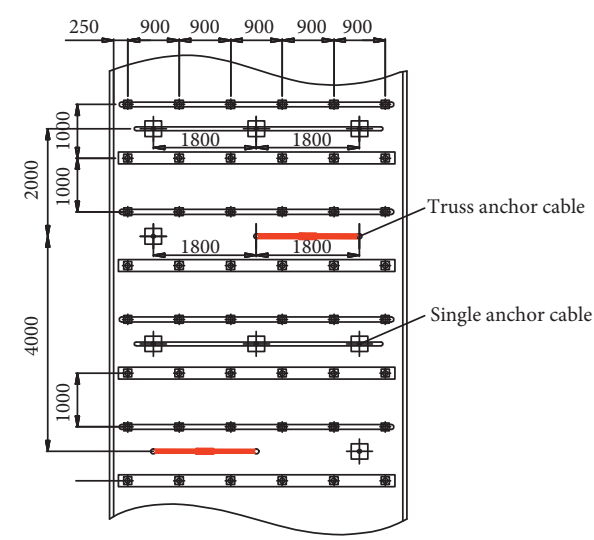

(b)

FIGURE 11: Scheme of rock support system in the roadway. (a) Front view. (b) Top view.

subsequent 130205 working face of the recovery process, by the influence of superimposed support pressure, coal column stability again greatly reduced, may lead to destabilization of the roadway occurred in large deformation, and even cause serious economic losses

(2) No.2 coal seam thickness distribution is more uneven, and there is more gangue layer in the direct bottom; in view of this special geological structure design along the coal seam mid-waist line boring, forming a special roadway structure with coal body as the bottom plate, coal seam bottom plate coal quality is softer, so the stability of the bottom plate along the empty roadway compared with other similar roadway needs to pay more attention to consider

In response to the above problem, the "new prestressed truss anchor cable + single anchor cable + anchor rod + net + slurry spray" support method is adopted in 130205 section backwind flat road, and concrete hardened base plate is used to limit the coal body projection of the base plate. This asymmetric support system effectively reduces the maximum tensile stress of the coal rock body in the middle area of the roadway and improves the strength and resistance of the coal rock body [21-23]. This asymmetric support system can effectively reduce the maximum tensile stress in the central part of the roadway and improve the strength and resistance to deformation.

5.2. Parameters of Return Air Tunnel Support System. The stability of the surrounding rock of the retrieval tunnel is equally inseparable from the interaction between the support and the surrounding rock, and Figure 11 shows the flat section of the shaped section support along the hollow tunnel.

From Figure 11, the following can be seen:

(1) The roof anchors are $\$ 22 \mathrm{~mm} \times L 2500 \mathrm{~mm}$ left-hand threaded steel anchors, each anchor is $900 \mathrm{~mm}$ apart, the distance between the corner anchors on the side of the coal pillar gang and the coal pillar gang is $250 \mathrm{~mm}$, the anchors near the two gangs are inclined $15^{\circ}$ to the outside, and the rest of the anchors are arranged perpendicular to the roof. The truss anchor cable adopts two $\$ 22 \mathrm{~mm} \times L 11300 \mathrm{~mm}$ highstrength low relaxation prestressing steel strands, and the anchor cable near the gang is inclined $10^{\circ}$ to the outside, and there is another single anchor cable near the solid coal gang with the specification of ф22 $\mathrm{mm} \times L 10300 \mathrm{~mm}$

(2) $\$ 20 \mathrm{~mm} \times L 2300 \mathrm{~mm}$ threaded steel anchor rods were used in the solid coal gang, 5 anchor rods were arranged in a row, the distance between rows of anchor rods is $750 \mathrm{~mm} \times 1000 \mathrm{~mm}$, the upper anchor rods are $250 \mathrm{~mm}$ from the top plate, the anchor rods near the top plate were inclined upward by $15^{\circ}$, the anchor rods near the bottom plate are inclined downward by $10^{\circ}$, and the rest were arranged perpendicular to the gang

(3) The coal pillar gang uses $\$ 20 \mathrm{~mm} \times L 2300 \mathrm{~mm}$ threaded steel anchor rods, 6 anchor rods are arranged in a row, the distance between rows of anchor rods is $750 \mathrm{~mm} \times 1000 \mathrm{~mm}$, the upper anchor rods are $250 \mathrm{~mm}$ from the top plate, the anchor rods near the top plate are inclined upward by $15^{\circ}$, the anchor rods near the bottom plate were inclined downward by $10^{\circ}$, and the rest were arranged perpendicular to the roadway gang

5.3. Numerical Simulation Analysis of Support. 130205 along the empty roadway roof staggered with truss anchor cable and single anchor cable joint support form greatly enhances the surrounding rock support difficult area of the bearing performance and the use of numerical simulation method to analyze the support form under the roadway surrounding rock pressure characteristics, as shown in Figure 12. Although the distribution of the second invariant of deviatoric 


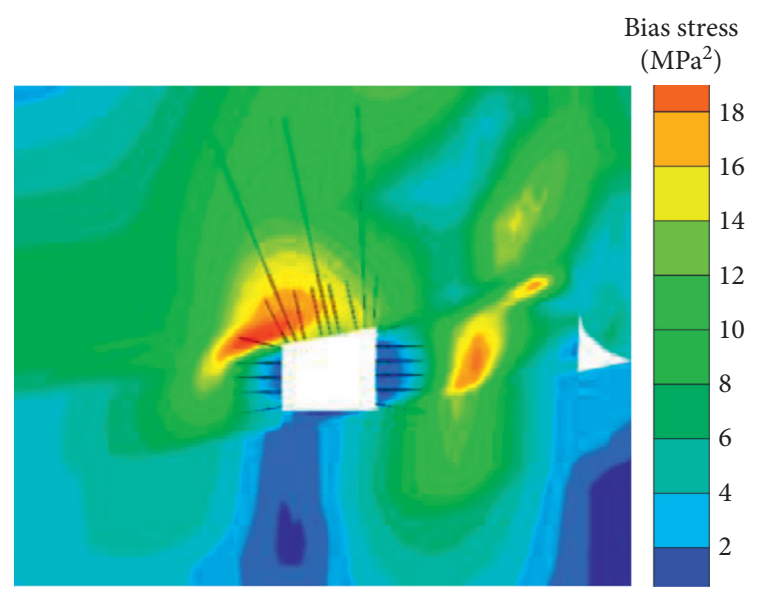

Figure 12: Cloud diagram of the second invariant of deviatoric stress distribution for the effect of rock support in the roadway.

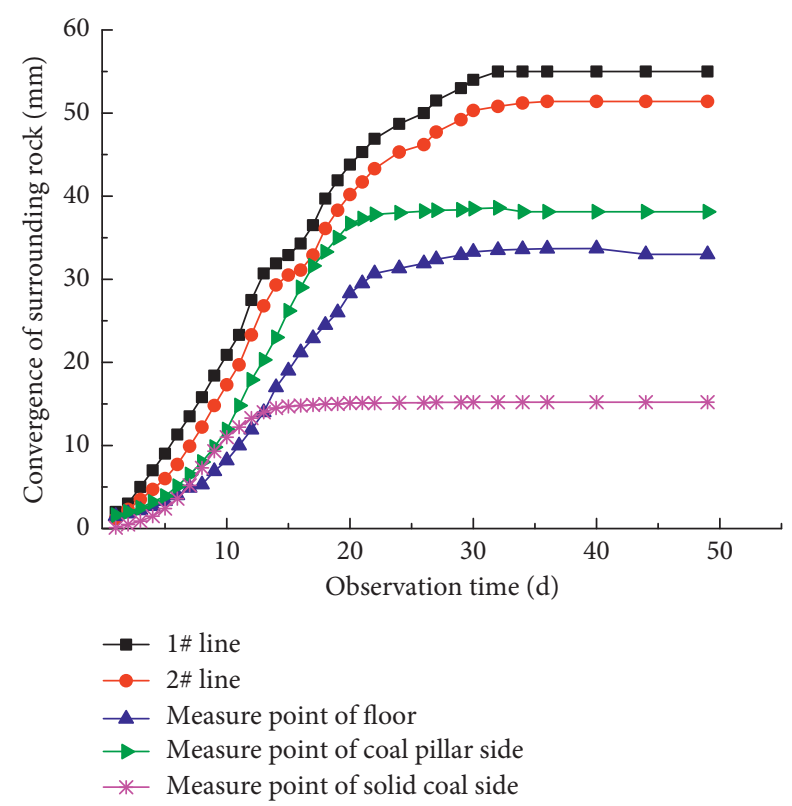

FIgURE 13: Field mine pressure observation results.

stress in the shallow surrounding rock of the roof still shows asymmetry, its overall distribution is relatively uniform, the stress concentration area at the shoulder nest of solid coal is relieved, and the range of low stress area on the gang side of coal pillar is also reduced. According to the reciprocal influence relationship between the top plate and gang deformation of the roadway, the coupling effect of its asymmetric support can alleviate the roadway deformation, thus effectively limiting the harmful deformation damage of the surrounding rock, achieving the uniformity of nonuniform load, and thus maintaining the roadway stability.

\section{Mineral Pressure Observation and Analysis of Results}

This return airway is continuously observed for the convergence of the tunnel surrounding rock while it is dug. Two lines are set up at the top plate to monitor the convergence of the surrounding rock after tunneling, line 1 is $0.8 \mathrm{~m}$ near the coal pillar side, line 2 is $0.8 \mathrm{~m}$ near the solid coal side, and the monitoring points of the gang and bottom plate are all at their midline locations. The curve of the surrounding rock change after tunneling is shown in Figure 13. It can be seen that the process of surrounding rock stabilization after roadway boring is a dynamic process until the equilibrium state, the top and bottom plates and coal pillar gangs tend to stabilize at about $30 \mathrm{~d}$ roadway deformation, and the solid coal gangs tend to stabilize at $20 \mathrm{~d}$ after roadway boring. The maximum deformation of the top plate 1 line is $55 \mathrm{~mm}$, the maximum deformation of the top plate 2 line is $51 \mathrm{~mm}$, the maximum displacement of the coal pillar gang is $38 \mathrm{~mm}$, and the maximum displacement of the solid coal gang is $15 \mathrm{~mm}$. Monitoring results, this support method is effective for the maintenance of the roadway.

\section{Conclusion}

(1) Usually, the roadway is arranged within the internal stress field, so that the surrounding rock of the roadway is in a low stress state, which greatly improves the mechanical environment of the surrounding rock. In this paper, this paper establishes a simple mechanical model of inclined coal seam and derives the formula of the influence range of "internal stress field" in inclined coal seam

(2) Using FLAC3D simulation technology, it is concluded that along the coal seam inclination direction, with the increase of coal pillar width, the second invariant of deviatoric stress curve in the coal pillar shows the transformation from single hump shape to positive trapezoid shape to double hump shape, the solid coal stress gradually shifts to the coal pillar side with the increase of coal pillar width, and the reasonable coal pillar width is usually less than the width of the coal pillar when the extreme value of the second invariant of deviatoric stress appears

(3) The top plate surrounding rock on the side of coal pillar has a high second invariant of deviatoric stress compared with the top plate on the side of solid coal, and the top plate surrounding rock has asymmetric destructive property; in the inclined coal seam, it is usually taken as reasonable narrow coal pillar width at the minimum fluctuation value of the second invariant of deviatoric stress

(4) The internal integrity of the coal pillar directly determines the stability degree along the empty roadway. With the compaction of coal gangue in the mining area after the working face, the fissures on both sides of its narrow coal pillar are also gradually developed, its bearing capacity continues to decrease, and the existence of a certain range of elastic core area in the middle of the coal pillar is crucial to the stability of the coal pillar and the roadway

(5) A new type of truss anchor cable joint support method is proposed for asymmetric control of the 
roadway, with high-strength anchors placed in each row of the roof and gang to reinforce the coal body, and the top plate is staggered with a single anchor cable and truss anchor cable to enhance the bearing capacity of the difficult area of support, thus improving the stress environment of the surrounding rock and preventing the malignant collapse of the coal pillar gang roof and shoulder sockets

\section{Data Availability}

All data used to support the findings of this study are included within the article, and there are not any restrictions on data access.

\section{Conflicts of Interest}

The authors declare no conflicts of interest.

\section{Acknowledgments}

The work was supported by the Engineering Laboratory of Deep Mine Rockburst Disaster Assessment Open Project (LMYK2020005) and the National Natural Science Foundation of China (Nos. 51574243, 51404269, and 51674253).

\section{References}

[1] Z. Zhang, J. Bai, Y. Chen, and S. Yan, "An innovative approach for gob-side entry retaining in highly gassy fullymechanized longwall top-coal caving," International Journal of Rock Mechanics and Mining Sciences, vol. 80, pp. 1-11, 2015.

[2] Z. Yang, C. Liu, S. Tang, L. Dou, and J. Cao, "Rock burst mechanism analysis in an advanced segment of gob-side entry under different dip angles of the seam and prevention technology," International Journal of Mining Science and Technology, vol. 28, no. 6, pp. 891-899, 2018.

[3] Z. Zheng, Z. Q. Yang, H. Z. Zhu et al., "Study on reasonable coal-pillar width and surrounding-rock control of gob-side irregular roadway in inclined seam," Journal of Mining \& Safety Engineering, vol. 36, no. 2, pp. 223-231, 2019.

[4] A. H. Wilson, "The stability of underground workings in the soft rocks of the coal measures," International Journal of Mining Engineering, vol. 1, no. 2, pp. 91-187, 1983.

[5] J. B. Bai, C. J. Hou, and H. F. Huang, "Numerical simulation study on stability of narrow coal pillar of roadway driving along goaf," Chinese Journal of Rock Mechanics and Engineering, vol. 23, no. 20, pp. 3475-3479, 2004.

[6] G. X. Xie, K. Yang, and Q. M. Liu, "Study on distribution laws of stress in inclined coal pillar for fully-mechanized top-coal caving face," Chinese Journal of Rock Mechanics and Engineering, vol. 25, no. 3, pp. 545-549, 2006.

[7] F. L. He and G. C. Zhang, "Asymmetric failure and control measures of large cross-section entry roof with strong mining disturbance and fully-mechanized caving mining," Chinese Journal of Rock Mechanics and Engineering, vol. 35, no. 4, pp. 806-818, 2016.

[8] C. J. Hou and X. H. Li, "Stability principle of surrounding rock structure in fully mechanized driving along next goaf," Journal of China Coal Society, vol. 26, no. 1, pp. 1-7, 2001.

[9] W. H. Zha, X. Li, X. Z. Hua et al., "Impact and application on narrow coal pillar for roadway protecting from fracture position of upper roof," Journal of China Coal Society, vol. 39, no. S2, pp. 332-338, 2014.

[10] Z.-Q. Yang, C. Liu, G.-A. Wang, G.-W. Li, and F.-S. Li, "Structural characteristics analysis of overlying rocks and prevention measures with a long-wall face passing across abandoned roadways: a case study," Shock and Vibration, vol. 2021, Article ID 6665341, 15 pages, 2021.

[11] T. Li, T. T. Mei, G. Q. Li et al., "“Mechanism study of coal and gas outburst induced by rockburst in "three-soft" coal seam," Chinese Journal of Rock Mechanics and Engineering, vol. 30, no. 6, pp. 1283-1288, 2011.

[12] J. G. Guo, W. G. Wang, F. L. He et al., "Main roof break structure and surrounding stability analysis in gob-side entry with fully-mechanized caving mining," Journal of Mining \& Safety Engineering, vol. 36, no. 3, pp. 446-454+464, 2019.

[13] G. ..C. Zhang, L. J. Chen, Z. J. Wen et al., "Squeezing failure behavior of roof-coal masses in a gob-side entry driven under unstable overlying strata," Energy Science \& Engineering, vol. 8, 2020.

[14] Z.-q. Yang, H.-m. Wang, D.-q. Sun, X.-j. Ma, M.-b. Xu, and N.-X. Si, "Study on occurrence mechanism of coal pillar in L-Shaped zone during fully mechanized mining period and prevention technology," Shock and Vibration, vol. 2021, Article ID 6638009, 15 pages, 2021.

[15] M. B. Wold, L. D. Connell, S. K. Choi et al., "The role of spatial variability in coal seam parameters on gas outburst behaviour during coal mining," International Journal of Coal Geology, vol. 75, no. 1, pp. 1-14, 2008.

[16] C. Liu, Z. Yang, P. Gong et al., "Accident analysis in relation to main roof structure when longwall face advances toward a roadway: a case study," Advances in Civil Engineering, vol. 2018, Article ID 3810315, 11 pages, 2018.

[17] G. C. Zhang, F. L. He, L. S. Jiang et al., "Analytical analysis and field observation of break line in the main roof over the goaf edge of longwall coal mines," Mathematical Problems in Engineering, vol. 2016, Article ID 4720867, 11 pages, 2016.

[18] Z. Yang, L. Dou, C. Liu, M. Xu, Z. Lei, and Y. Yao, “Application of high-pressure water jet technology and the theory of rock burst control in roadway," International Journal of Mining Science and Technology, vol. 26, no. 5, pp. 929-935, 2016.

[19] W. H. Peng and A. H. Lu, "Numerical simulation of layered crack and failure of roadway surrounding rock under the action," Journal of Mining \& Safety Engineering, vol. 25, no. 2, pp. 213-216, 2008.

[20] G. A. Zhu, L. M. Dou, Z. L. Li et al., "Mining-induced stress changes and rock burst control in a variable-thickness coal seam," Arabian Journal of Geosciences, vol. 5, no. 9, pp. 365-376, 2016.

[21] Z. Z. Zhang, M. Deng, J. B. Bai et al., "Strain energy evolution and conversion under triaxial unloading confining pressure tests due to gob-side entry retained," International Journal of Rock Mechanics and Mining Sciences, vol. 126, pp. 1-10, 2020.

[22] M. G. Qian, P. W. Shi, and J. L. Xu, Mining Pressure and Strata Control, pp. 105-125, China University of Mining and Technology Press, Xuzhou, China, 2010.

[23] L. Li, J. B. Bai, and X. Y. Wang, "Ration position and control technique of roadway driving along next goaf in fully mechanized top coal caving face," Journal of China Coal Society, vol. 37, no. 9, pp. 1564-1569, 2012. 